\title{
PRODUCING AND VISUALIZATING 3D BUILDING GEODATABASE AS A PART OF 3D CADASTRE PROJECT
}

\author{
A. Guntel ${ }^{1}$, A. C. Aydinoglu ${ }^{2}$ \\ 1 Mescioglu Muhendislik ve Musavirlik A.S., Ankara, Turkey \\ 2 GTU, Department of Geomatics Engineering, Gebze Technical University, Kocaeli, Turkey
}

KEY WORDS: Geodatabase, 3D City Model, Visualization, GML, Photogrammetry, Architectural Project

\begin{abstract}
:
Digital data production possibilities have developed with the emerging technologies, and it has become possible to use different data formats together. The usability of three-dimensional (3D) data on various application areas has increased with the multidimensional use of geographic data in established information systems, for 3D visualization, presentation, and analysis. Topography-related analyzes such as digital elevation models, digital terrain models, slope maps and visibility maps can be made from geographic data sets produced in 3D. In addition, the use of 3D data in Building Information Modeling (BIM) has added various innovations for geographic data analysis. In this study, a geographic database was established by taking the vector data produced in the 3D Cadastre project that was carried out by the General Directorate of Land Registry and Cadastre as an example. Data obtained from photogrammetry and architectural projects were used in accordance with the OGC CityGML standard. After creating 3D building database in GIS environment, as result of various visualization and analysis techniques, the contributions of this project to BIM were revealed for various applications such as real estate valuation, disaster management, renewable energy, 3D city models, and smart city projects.
\end{abstract}

\section{INTRODUCTION}

With the increase of the possibilities in the production of geographical data and using it in different applications, geographic data has started to be used in a large extent activity carried out in many fields, from scientific research to applications. The need for digital data and the usability of different data formats have been increasing with the developing technologies and the awareness of multidisciplinary projects. In the information systems established in line with these basic objectives where sustainability exists, its usability has increased in application areas for 3D visualization, presentation, and analysis.

3D city model provides a digital representation of the Earth's surface and it's related objects such as building, tree, vegetation, and some manmade feature belonging to urban areas. 3D city models are a digital model of a city containing the graphic representation of buildings and other objects in 2.5 or $3 \mathrm{D}$. (Singh et.al., 2013)

Management of buildings throughout their lifecycles starting from their construction can be carried out more easily and more effectively by means of information technologies. In this context, Building Information Modelling (BIM) concept have been proposed which is constituted according to interdisciplinary work conditions, which enables seeing the problems beforehand and can contribute to developing solutions. On the other hand, geographic information systems (GIS) are used for land administration, urban planning, real estate management (Döner et.al., 2011), environmental rearrangement, and transportation planning as a decision support system. For example, traditional cadastral systems generally provide only two-dimensional (2D) legal and geometric information about property units, however, today's valuation practices would benefit significantly from threedimensional (3D) information in order better to estimate and explain values of property units (Kara et.al., 2019).

A BIM includes very detailed and accurate information of a construction. Transforming the BIM to its corresponding geographic model helps answering many environmental questions efficiently. (Rafiee et.al., 2014) In addition, BIM that can be created by using mapping methods have also added different innovations to GIS and Building Information Modelling (BIM) applications (Kurwi, Sahar. 2019). From geographic data produced in three dimensions, topographyrelated analyzes such as digital elevation models and digital terrain models, slope maps and visibility analyzes can be made.

Along with the developing photogrammetry software and hardware technologies, imaging techniques and resolutions have increased to produce three-dimensional data. Besides conventional techniques such as Digital Elevation Models (DEM) and aerial images, high resolution satellite images with LASER scanning and terrestrial images with Close Range Photogrammetry are used for 3D city models (Singh et.al., 2013) For this reason, the use of vector 3D geographic data as well as images of topography and structures provided an advantage in data analysis. Thus, beyond the fact that they are 3D, the use of information systems established in line with our daily and scientific research needs, and the use of city models in GIS analysis has started to take place among the objectives of hardware and software technologies.

Due to the large size and complexity of the 3D geospatial data, the GIS software vendors face with many challenges for realizing the efficient storage, analysis, management, and visualization of the $3 \mathrm{D}$ city models based on the CityGML standard (Yao, et.al., 2018). Open Geospatial Consortium 
(OGC) works with ISO / TC 211 committee in the areas of digital geographic information and geomatics. In this context, the Geo-Marking Language (GML) developed by OGC is a language that enables modelling, storage, and sharing of the $3 \mathrm{D}$ geometry (Alkan et.al, 2020).

In this study, a case study has been developed for the use of data bases produced within the scope of institutional applications. A $3 \mathrm{D}$ building database was established for various visualization and query purposes.

\section{METHODOLOGY AND APPROACH}

\subsection{Data and Test Area}

The project of Production of 3D City Models and Creation of 3D Cadastre Bases, carried out by the General Directorate of Land Registry and Cadastre (TKGM), has been the subject of this research to produce $3 \mathrm{D}$ city models and the creation of $3 \mathrm{D}$ cadastre databases.

In this study, case study has been developed for the use of data bases produced within the scope of institutional applications. A $3 \mathrm{D}$ building database was established for various visualization and query purposes. In this project, it is aimed to update the cadastral maps in the settlement areas (province, district and neighborhood) determined throughout Turkey to support digital cadastre and land registry information and to use them in all kinds of planning, project design and GIS applications. In this project, oblique aerial photographs, roof prints, real orthophoto images, and data produced from architectural projects approved by municipalities have been used. The test study area is located in the central district of Amasya province (Figure 1) and determined within the scope of this study covering the data of approximately 200 parcels and 180 buildings (Figure 2).

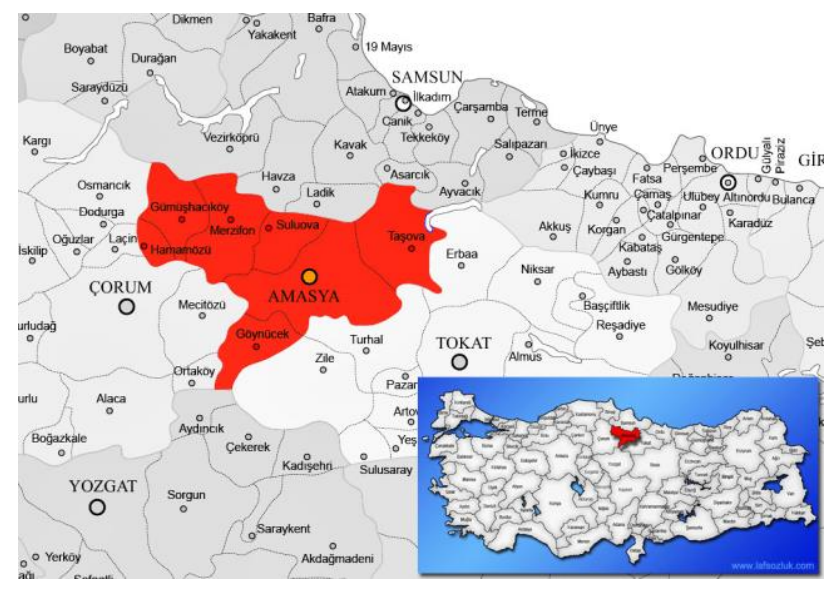

Figure 1. Project Area

Within the scope of the 3D cadastre project, oblique aerial photographs were provided by TKGM and roof and architectural project models were produced by Mescioglu Engineering Company for this area.

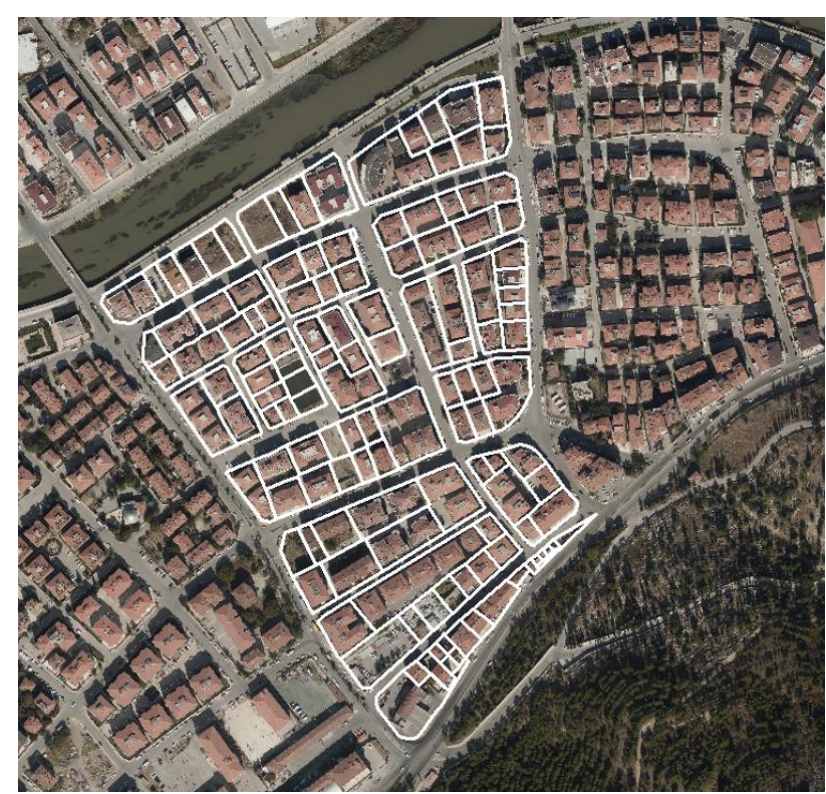

Figure 2. Gökmedrese County

\subsection{D Database Production based on CityGML}

The city models produced within the scope of this project are at LoD 0,1 and 2 according to the CityGML definition (Yao, et.al., 2018). If there are architectural projects representing the buildings in the project area, the generated data is defined at LoD 2.3 level.

In addition to the vector data obtained from the photogrammetry projects, the architectural projects approved and scanned by the municipalities in the project area were digitized. In this digitization process, rooms, independent units combining rooms, and building geometries from floor plans were produced. The architectural vector data was converted into a real coordinate system with the roof projection lines produced by the photogrammetry method (Figure 3 ).

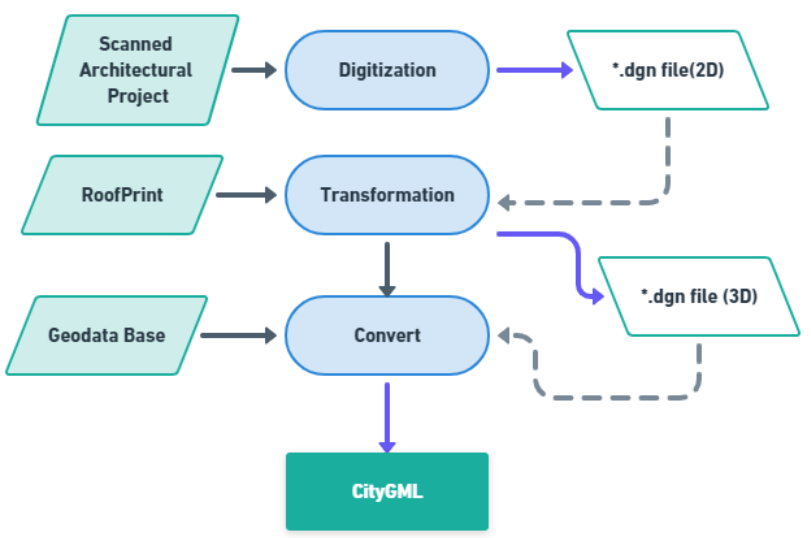

Figure 3. Workflow of GML Generation

Besides the vector data produced with the digitization process, detailed qualitative information such as room usage, architectural project approval dates, and elevator were produced 
as a working flow. The produced qualitative and quantitative data were produced in CityGML format, which is an OGC standard, and in OBJ formats that only contain geometry (Figure 4).

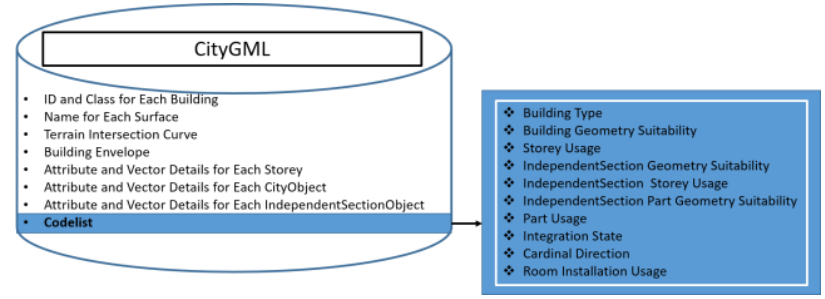

Figure 4. Contents of CityGML

Beyond the visualization of $3 \mathrm{D}$ city models, which are the subject of the study, city models can be associated with the qualitative information in TKGM's and General Directorate of Census and Citizenships (NVI)'s information system projects (Figure 5).

FME software was used to transfer the generated GML format data to the 3D geodatabase (Figure 6). Before the 3D geodatabase was created, attention was paid to include all the features in this data analysis. The required datasets that provide advantages to the queries to be made in the database were analyzed.

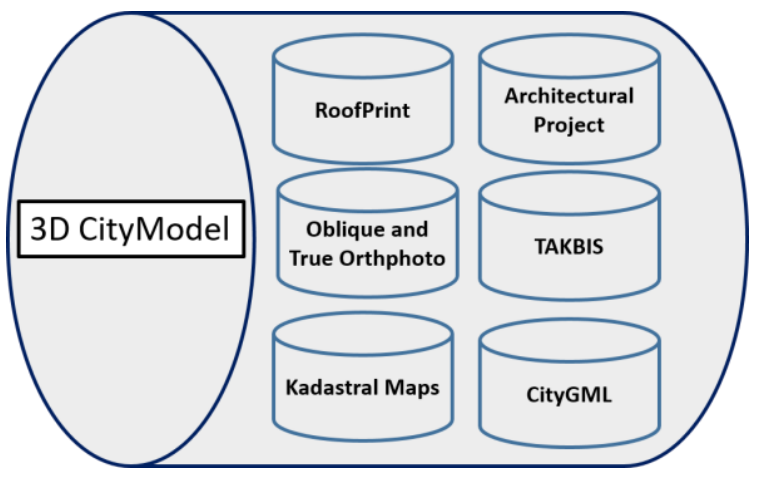

Figure 5. Contents of 3D City Model

It is aimed to draw attention to the use of 3D geodatabase in the projects providing added value. In this context, datasets such as building floor numbers and elevator information are associated with building structures, while details such as building facade information for independent units and usage types for each room were integrated into the database.

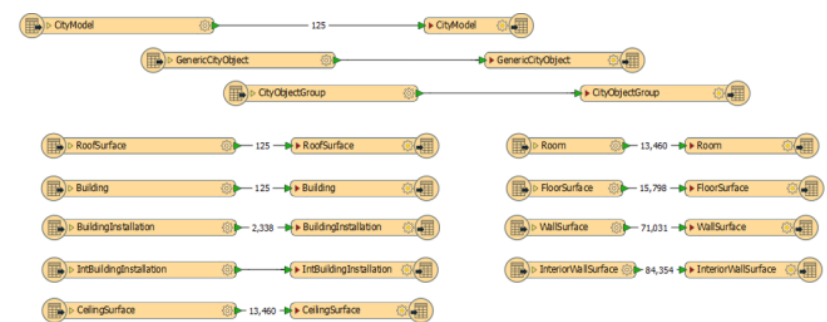

Figure 6. Work schema in FME

\section{3D VISUALIZATION AND ANALYSIS}

CityGrid or CityGenius software was used to visualize the datasets produced within the scope of this project. These programs also have visualization capability like displaying mass models without pictures, showing related databases on models, visibility analysis, etc. However, in these visualization programs, no query and analysis can be made according to the produced qualitative information. Figure 7 shows an example city model produced with photogrammetric technique.

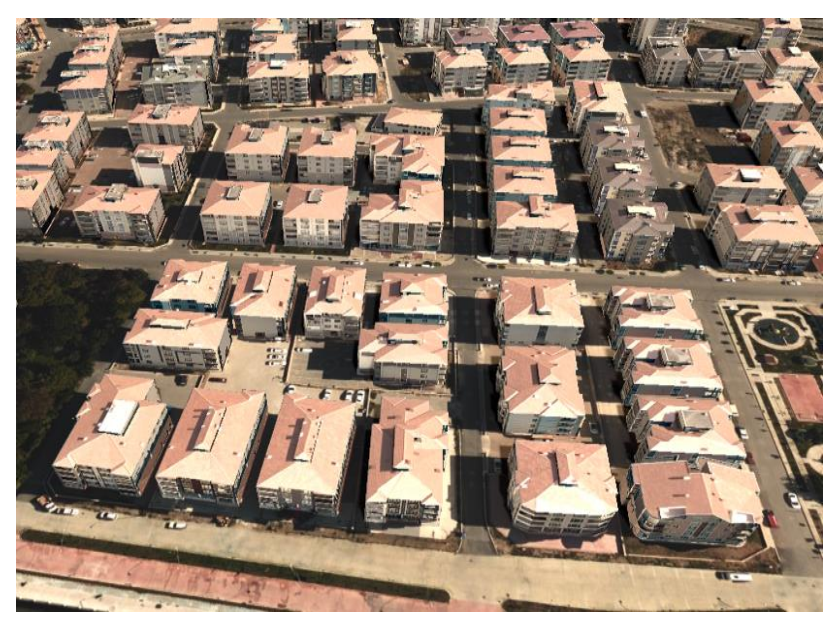

Figure 7. Example of City Model

LoD 2.0 model with texturing model can be visualized on Citygrid. As seen on Figure 8, Citygrid is allowed to visualize the oblique images with four sides, each 3D models in the one Windows.

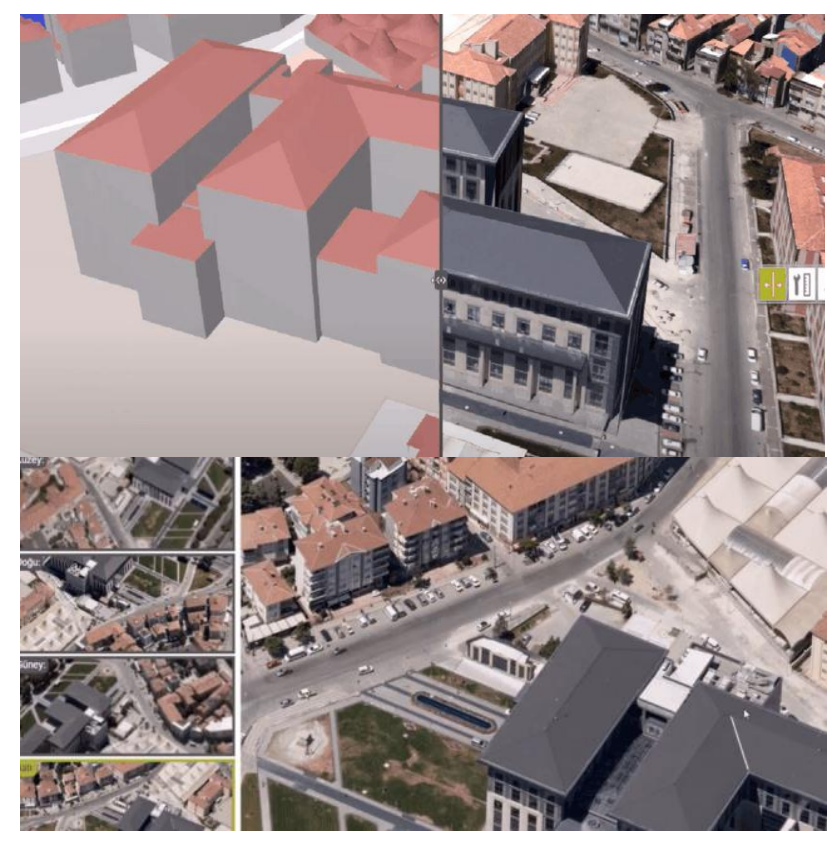

Figure 8. Example of Visualization-2 (CityGrid)

Viewshed analysis was also made with this software. According to application needs, CityGrid (Figure 9) and City Genius 
(Figure 10) software can visualize viewshed analyze results dynamically.

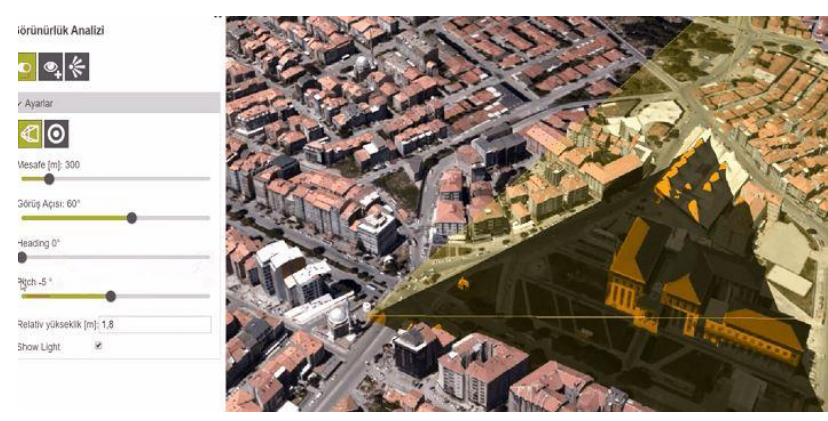

Figure 9. Example of Viewshed-1 (CityGrid)

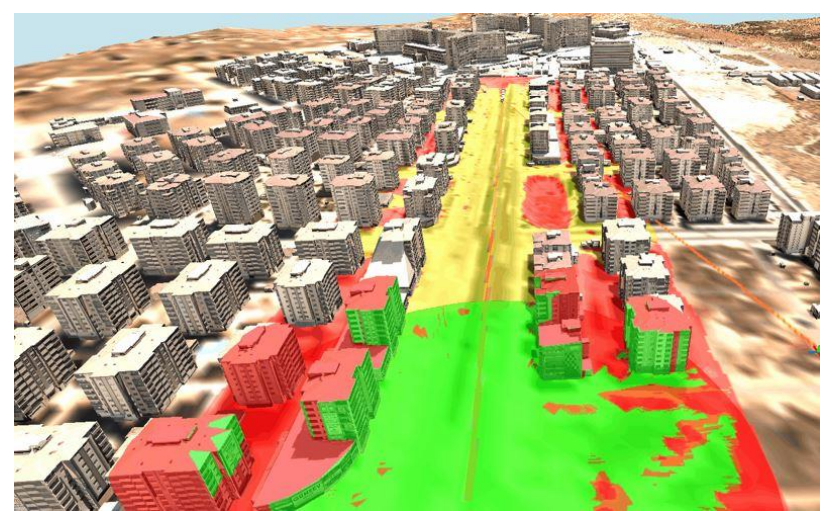

Figure 10. Example of Viewshed-2 (CityGenius)

The 3D Geodatabase which was provided by TKGM have information about 3D building model. Figure 11 is an example of 3D geodatabase on ArcScene.

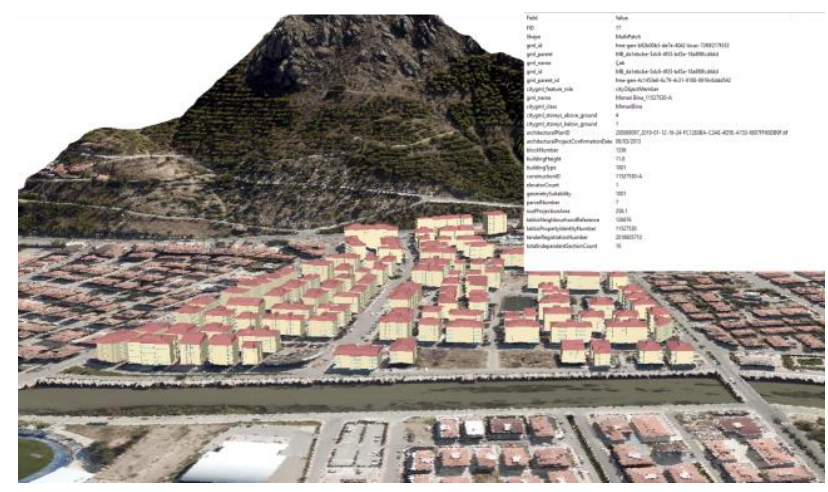

Figure 11. Example of 3D Geodatabase

Various queries can be made on 3D geodatabase model and many problems can be solved about Real Estate Appraisal. Figure 12 shows a classification of storey usage for independent unit

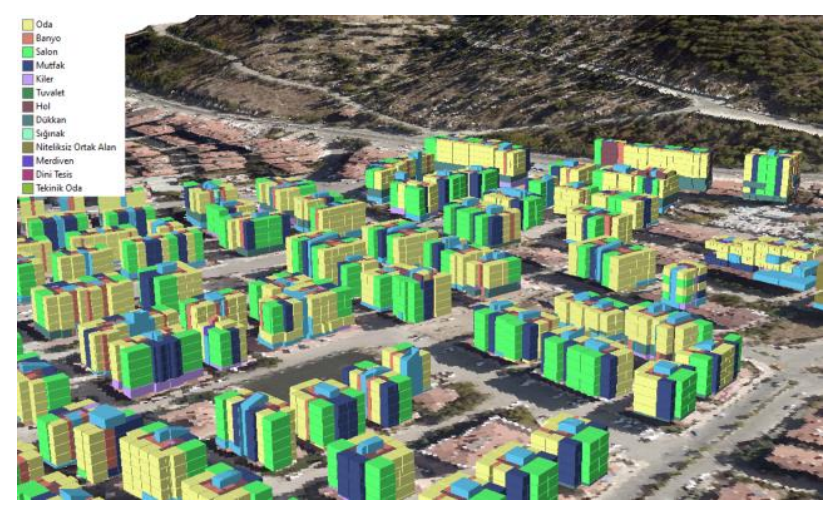

Figure 12. Classification of Storey Usage for Independent Unit

Storey usage for independent unit is also important for Disaster and Emergency Management. Storeys above ground can be found from the 3D Geodatabase as seen on Figure 13.

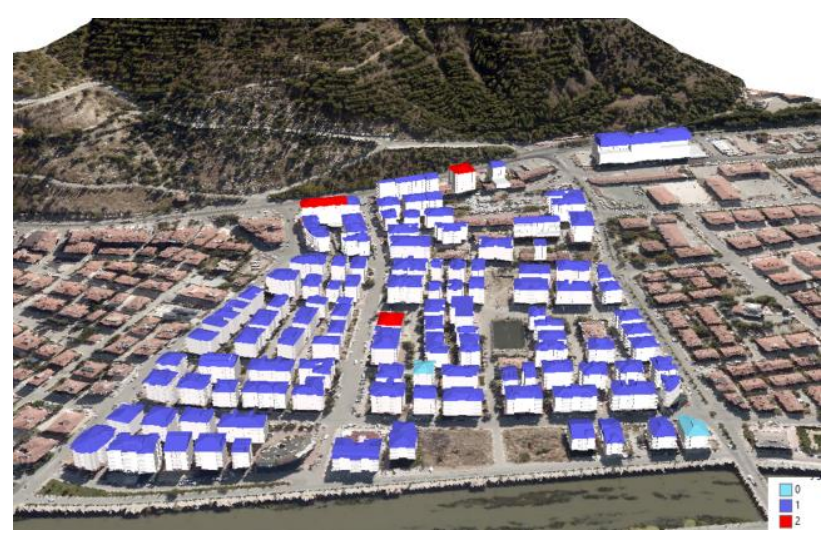

Figure 13. Classification of Storeys Above Ground

\section{DISCUSSION AND CONCLUSION}

In the $3 \mathrm{D}$ geodatabase produced in this study, it is possible to define the building and building sub-units together with the other elements. The project realized within the body of TKGM enables various application project that have emerged with the production of building models in large areas. 3D city models representing building and independent section units can be visualized with different open software. These datasets can be interoperable with attribute information and information from other database.

Besides the production of 3D database, many attribute information has become used in applications as a result of relating with other databases. In addition to the 2-dimensional data management possibilities in GIS, the distance, view and noise characteristics can be obtained automatically and semiautomatically with the three-dimensional visualization of the data. The interoperability of data representing building sub-units or building qualitative attribute information from other databases provides decision support opportunities in various applications. As a result of the question and analysis processes to be carried out on this $3 \mathrm{D}$ database; solutions can be offered for Building Information Modeling (BIM), Real Estate 
Appraisal, Disaster and Emergency Management, Renewable energy, 3D city models, and various Smart city projects.

Requirements for developing data standards increase with the accelerating usability of city models and 3D GIS datasets in every project. For the interoperability of 3D building information at the national level, 3D city model standards should be integrated with the themes of the Turkish National Geographic Information System (TUCBS) infrastructure. There is a need to analyze this $3 \mathrm{D}$ geodatabase produced in different application areas, in visualization software, and to research the usability of city models on different platforms such as mobile applications.

\section{ACKNOWLEDGEMENTS}

We would like to thank the General Directorate of Land Registry and Cadastre (TKGM) and the contractor Mescioğlu Engineering Company for providing sample datasets.

\section{REFERENCES}

Alkan M., Surmeneli H.G., 2020: 3D cadastral standard definition and development using international standards for Turkey cadastral system. Journal of Geodesy and Geoinformation(10.9733/JGG.2020R0005.E), Volume:7, Issue:1.

Döner F., Bıyık C., Demir O., 2011: Dünyada Üç Boyutlu Kadastro Uygulamaları. HKMO Jeodezi, Jeoinformasyon ve Arazi Yönetimi Dergisi 2011/2.

Kara A., Oosterom P.V., Çağdaş V., Işıkdağ Ü., Lemmen C., 2019: 3 Dimensional data research for property valuation in the context of the LADM Valuation Information Model. Elsevier, Land Use Policy, 0264-8377.

Kurwi, Sahar. 2019: Integrating BIM and GIS for Design Collaboration in Railway Projects. A Doctoral Thesis submitted in partial fulfilment of the requirements for the award of Doctor of Philosophy of Loughborough University Loughborough's Research Repository.

Rafiee A., Dias E., Fruijtier S., Scholten H., 2014: From BIM To Geo-Analysis: View Coverage And Shadow Analysis By BIM/GIS Integration. 12th International Conference on Design and Decision Support Systems in Architecture and Urban Planning, DDSS 2014.

Singh S.P., Jain K., Mandla V.R., 2013: Virtual 3D City Modeling: International Archives of the Photogrammetry, Remote Sensing and Spatial Information Sciences, Volume XL2/W2,Techniques and Applications. ISPRS 8th 3DGeoInfo Conference \& WGII/2 Workshop, 27-29 November 2013.

Yao Z., Nagel C., Kunde F., Hudra G., Philipp W., Donaubauer A., Adolphi T., Kolbe T.H., 2018: 3dcitydb - A 3D Geodatabase Solution For The Management, Analysis, And Visualization Of Semantic 3D City Models Based On CityGML. Open Geospatial Data, Software and Standards (2018) 3:5. 